\title{
The Impact of Fructose on Renal Function and Blood Pressure
}

\author{
Marek Kretowicz, ${ }^{1}$ Richard J. Johnson, ${ }^{2}$ Takuji Ishimoto, ${ }^{2}$ \\ Takahiko Nakagawa, ${ }^{2}$ and Jacek Manitius ${ }^{1}$ \\ ${ }^{1}$ Department of Nephrology, Hypertension and Internal Medicine, Collegium Medicum in Bydgoszcz, \\ Nicolaus Copernicus University in Toruń, ul. Skłodowskiej-Curie 9, 85-094 Bydgoszcz, Poland \\ ${ }^{2}$ Division of Renal Diseases and Hypertension, University of Colorado Denver, Denver, CO 80045, USA \\ Correspondence should be addressed to Marek Kretowicz, markkret@neostrada.pl
}

Received 20 April 2011; Revised 17 June 2011; Accepted 17 June 2011

Academic Editor: Franca Anglani

Copyright ( $) 2011$ Marek Kretowicz et al. This is an open access article distributed under the Creative Commons Attribution License, which permits unrestricted use, distribution, and reproduction in any medium, provided the original work is properly cited.

Fructose is a sugar present in sucrose, high-fructose corn syrup, honey, and fruits. Fructose intake has increased markedly in the last two centuries, primarily due to increased intake of added sugars. Increasing evidence suggests that the excessive intake of fructose may induce fatty liver, insulin resistance, dyslipidemia, hypertension, and kidney disease. These studies suggest that excessive intake of fructose might have an etiologic role in the epidemic of obesity, diabetes, and cardiorenal disease.

\section{Introduction}

Fructose is a monosaccharide that is widely available in natural food sources such as fruits and honey. However, in most countries the main source of fructose is from sucrose, a disaccharide composed of equal portions of fructose and glucose. In the United States another major source of fructose is high-fructose corn syrup (HFCS), which is a commercial liquid product consisting of fructose and glucose in varying proportions, but which in soft drinks is usually 55\% fructose and $45 \%$ glucose.

Fructose intake has increased markedly over the last 2 centuries, primarily due to the increasing intake of sucrose and HFCS [1-3]. In particular, the introduction of HFCS in the 1970s resulted in an accelerated intake of added sugars in the USA, in part because HFCS was inexpensive and could be easily mixed in with processed foods [4]. It has been suggested that the increase in added sugars worldwide may partially explain the marked increase in frequency of overweight and obese humans and may explain the rising frequency of metabolic syndrome, diabetes, hypertension, and cardiovascular diseases (coronary artery disease, congestive heart failure, stroke, and chronic kidney disease) [1-3].

Fructose is absorbed into the intestine enterocyte by the Glut-5 specific transporter. While some fructose is metabolized in the small intestinal wall, much of it is passed via the portal vein to the liver, with perhaps 20 to $30 \%$ escaping into the systemic circulation $[5,6]$. Within the hepatocyte, fructose is phosphorylated to fructose-1-phosphate by fructokinase. Because this reaction has no negative feedback system, if sufficient fructose is present, intracellular phosphate and ATP depletion can transiently occur. This results in the generation of AMP which is metabolized by AMP deaminase to inosine monophosphate and eventually to uric acid [5]. The transient ATP depletion has some similarities to ischemia and can result in arrest of protein synthesis with the induction of oxidative stress and inflammation [7-9].

Circulating fructose is taken up by a variety of cell types, including endothelial cells, but also is excreted into the urine where it is absorbed via the Glut-5 transporter into the S3 segment of the proximal tubule. This cell also expresses fructokinase; as such, the metabolism of fructose by this proximal tubular cell can also lead to local oxidative stress and inflammation $[8,10]$.

\section{Biological Effects of Fructose}

2.1. Liver Effects: Fatty Liver and Glycogen Accumulation. Fructose is known to stimulate fat accumulation in the liver by both increasing synthesis and blocking fat oxidation $[11,12]$. These effects are independent of energy intake [12-14]. Perhaps not surprisingly, clinical studies have linked 


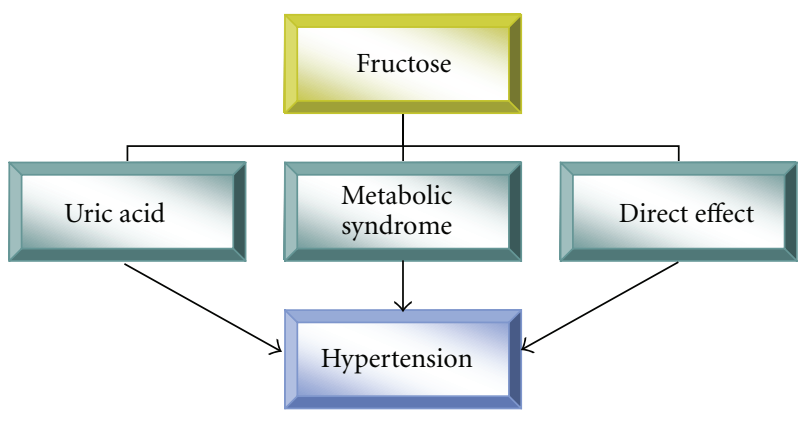

Figure 1: Proposed pathogenesis of fructose-induced hypertension.

the intake of excessive fructose with the development of nonalcoholic fatty liver disease in humans, and the amount of fructose ingested correlates with the risk for progression to cirrhosis $[15,16]$.

Fructose is also known to stimulate glycogen accumulation in the liver $[17,18]$, which primarily appears to be due to inhibiting glycogenolysis due to inhibition of glycogen phosphorylase [19].

2.2. Insulin Resistance and Islet Dysfunction. Fructose intake has been shown to induce insulin resistance in rats $[20,21]$; fructose can also induce insulin resistance in humans [22]. The proposed mechanisms are complex but may include a consequence of hepatic lipid deposition, with diacylglycerol accumulation leading to activation of protein kinase [22, 23] or via the hepatic stimulation of PGC- $1 \beta$ [24]. Some of the effects may also be due to fructose-induced hyperuricemia with effects on endothelial and adipocyte function [14, 25]. However, the lowering of uric acid with allopurinol did not prevent the development of insulin resistance in subjects administered large doses ( $200 \mathrm{~g} / \mathrm{d}$ for two weeks) of fructose [26].

Fructose intake may also accelerate the development of type 2 diabetes in rats, possibly by accelerating islet dysfunction via induction of mild islet inflammation and oxidative stress $[12,27]$. One study suggests that this might be due in part to the effects of systemic uric acid that increase in response to fructose (or sucrose) ingestion [12].

Fructose may also stimulate the production of advanced glycation end products (AGEs) that have been shown to be toxic in diabetes [28]. Indeed, chronic fructose ingestion has been associated with the accelerated formation of cataracts in diabetic rats [29].

Intake of sugary soft drinks has also been associated with the development of obesity and diabetes. [30, 31] Indeed, a recent meta-analysis by Malik et al. found a strong independent relationship between the intake of sugarcontaining soft drinks with the subsequent development of diabetes [32].

2.3. Obesity. Fructose does not acutely stimulate leptin or insulin release and hence may not trigger normal satiety responses [33]. In addition, added sugars such as sucrose have been found to trigger dopamine responses in the ventral and dorsal striatum, which chronically may lead to downregulation of the D2 receptors and sugar bingeing [34].
Fructose intake can also induce a central leptin resistance in rats, leading to increased food intake and the development of visceral obesity [35]. Interestingly, rats on a high-fructose diet may not show an increase in overall body weight unless it is associated with diets high in fat [36].

2.4. Hypertension and Vascular Effects. Fructose intake from added sugars is also associated with elevated blood pressure in humans [37], and diets low in added sugar have been reported to lower blood pressure [38]. Furthermore, the acute ingestion of fructose $(60 \mathrm{~g})$ can increase systolic blood pressure in humans, and this is not seen in subjects given the same dose as glucose [39]. In addition, in one study, overweight men were administered $200 \mathrm{~g}$ fructose daily for two weeks and sustained a significant increase in ambulatory blood pressure [26].

Studies in experimental animals have confirmed that fructose can raise blood pressure. Interestingly, the increase in blood pressure in response to fructose is better observed by tail cuff measurement as opposed to intra-aortic telemetry $[40,41]$. However, blood pressure rises in response to sucrose or fructose diet by telemetry during the first hours of feeding $[12,42]$.

The mechanism of hypertension in response to fructose is complex but appears to be mediated by increased sodium absorption in the intestine, by inhibition of systemic endothelial function, and by stimulation of the sympathetic nervous system $[14,43,44]$ (Figure 1). In addition, some of the effect of fructose to increase blood pressure may be the consequence of fructose-induced increases in intracellular and serum uric acid. First, fructose-induced hypertension in rats is largely ameliorated by lowering uric acid levels [40]. Second, in one study in overweight men, the rise in ambulatory blood pressure in response to $200 \mathrm{~g}$ of oral fructose per day for two weeks was blocked in those subjects concomitantly administered allopurinol [26].

2.5. Kidney Disease. Fructose and sucrose are also known to induce renal hypertrophy and tubulointerstitial disease in rats $[10,45,46]$. The mechanism may involve two central pathways (Figure 2). First, the rise in uric acid in response to uric acid may cause an afferent arteriolopathy resulting in glomerular hypertension [40]. Second, fructose may also be filtered into the urine where it is taken up in the S3 segment of the proximal tubule, leading to local intracellular generation of uric acid with oxidative stress and local inflammation [8].

The administration of fructose to rats with reduced renal function (the remnant kidney model) can accelerate the progression of renal disease, resulting in worse proteinuria, glomerulosclerosis, and tubulointerstitial fibrosis [47]. Fructose intake also impairs calcium absorption and reduces 25-OH Vitamin D and 1,25-dihydroxy Vitamin D levels in this model [48]. Furthermore, the intake of sugary soft drinks in humans is associated with increased prevalence of albuminuria [49]. Our group has also recently administered a low-fructose diet to subjects with stable chronic kidney disease for a period of 6 weeks. While we observed no effect on renal function during the period of the study, we did 


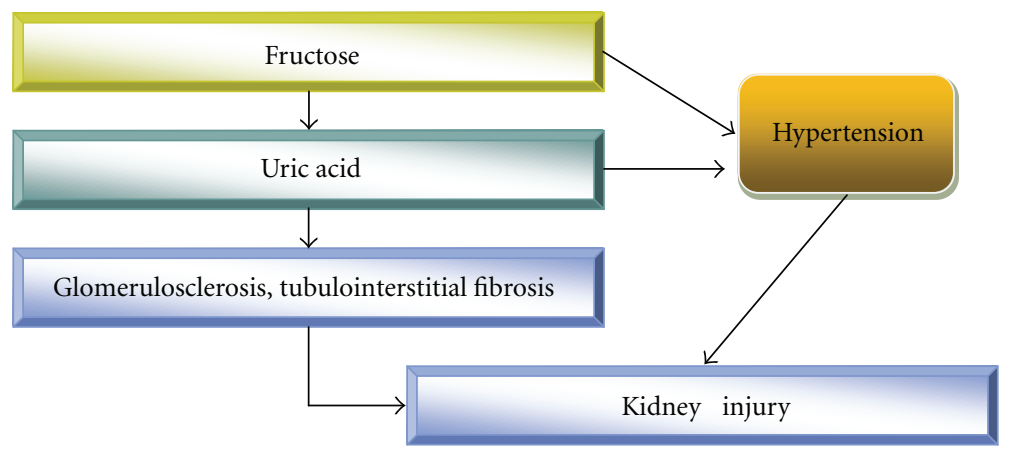

Figure 2: Mechanisms of kidney dysfunction in fructose-induced hypertension.

observe a reduction in inflammatory markers and a fall in blood pressure in subjects with the "dipper" physiology (i.e., those subjects whose blood pressure spontaneously falls at night during sleep) [49]. Clearly further studies are needed to determine if limiting added sugars may benefit subjects with kidney disease.

2.6. Role of Natural Fruits. While much work has focused on fructose as driving obesity, insulin resistance, and cardiorenal disease, not all fructose sources may be the same. Thus, natural fruits also are rich in antioxidants, ascorbate, polyphenols, potassium, and fiber that may counter the effects of fructose [13, 50]. Indeed, Forman et al. [51] reported that fructose intake did not correlate with elevated blood pressure in a population in which much of the fructose intake was from fruit, whereas Jalal et al. [37] found a strong association of fructose intake with blood pressure when the fructose content from natural fruits was excluded.

2.7. Caveats. While there is increasing evidence for a role for fructose as a contributory factor to obesity and metabolic syndrome, most of the data has relied on epidemiological studies, experimental models, and cell culture. In contrast, studies in which fructose or sucrose is administered to subjects have shown variable effects on metabolic parameters. In general, few metabolic effects are observed with fructose when it is given to young, healthy, and lean subjects [52-54]. This contrasts with studies in overweight/obese or insulin-resistant subjects in which metabolic effects from fructose or sucrose are commonly observed [22, 26, 55-58]. One potential explanation may relate to the absorption of fructose, which is known to increase with fructose exposure $[59,60]$. Fructose effects are also potentiated by glucose $[61,62]$, and most studies have only examined fructose alone. Most studies also show, both in animals and humans, that the effects of fructose are greater on postprandial lipids, fatty liver, and insulin resistance rather than on weight gain per se. Indeed, the effects of fructose may be more on inducing leptin resistance, and it may require the addition of high-fat diet to show the weight gain [35]. More studies are necessary before firm conclusions can be made. Nevertheless, the evidence that excessive intake of fructose may have multiple adverse effects on human health seems to be mounting.

\section{Conclusions}

There are likely multiple mechanisms driving the current epidemic of obesity, diabetes, and cardiorenal disease. Recent studies suggest that excessive fructose intake may be one of the causes. Future studies should investigate the effect of reducing fructose intake or blocking the metabolic effects of fructose as a means for preventing or treating these important diseases.

\section{Disclosure}

Dr. R. J. Johnson and Dr. T. Nakagawa have several patent applications on blocking the metabolic effects of fructose as a means to prevent or treat components of the metabolic syndrome. Dr Johnson also has a lay book, The Sugar Fix (Rodale, 2008).

\section{Acknowledgment}

This paper was supported by NIH Grant HL-68607.

\section{References}

[1] R. J. Johnson, M. S. Segal, Y. Sautin et al., "Potential role of sugar (fructose) in the epidemic of hypertension, obesity and the metabolic syndrome, diabetes, kidney disease, and cardiovascular disease," American Journal of Clinical Nutrition, vol. 86, no. 4, pp. 899-906, 2007.

[2] L. Tappy and K. A. Le, "Metabolic effects of fructose and the worldwide increase in obesity," Physiological Reviews, vol. 90, no. 1, pp. 23-46, 2010.

[3] P. J. Havel, "Dietary fructose: implications for dysregulation of energy homeostasis and lipid/carbohydrate metabolism," Nutrition Reviews, vol. 63, no. 5, pp. 133-137, 2005.

[4] G. A. Bray, S. J. Nielsen, and B. M. Popkin, "Consumption of high-fructose corn syrup in beverages may play a role in the epidemic of obesity," American Journal of Clinical Nutrition, vol. 79, no. 4, pp. 537-543, 2004.

[5] G. Van den Berghe, "Fructose: metabolism and short-term effects on carbohydrate and purine metabolic pathways," Progress in Biochemical Pharmacology, vol. 21, pp. 1-32, 1986.

[6] J. Hallfrisch, "Metabolic effects of dietary fructose," FASEB Journal, vol. 4, no. 9, pp. 2652-2660, 1990. 
[7] J. C. Bode, O. Zelder, H. J. Rumpelt, and U. Wittkamp, "Depletion of liver adenosine phosphates and metabolic effects of intravenous infusion of fructose or sorbitol in man and in the rat," European Journal of Clinical Investigation, vol. 3, no. 5, pp. 436-441, 1973.

[8] R. Cirillo, M. S. Gersch, W. Mu et al., "Ketohexokinasedependent metabolism of fructose Induces proinflammatory mediators in proximal tubular cells," Journal of the American Society of Nephrology, vol. 20, no. 3, pp. 545-553, 2009.

[9] O. Glushakova, T. Kosugi, C. Roncal et al., "Fructose induces the inflammatory molecule ICAM-1 in endothelial cells," Journal of the American Society of Nephrology, vol. 19, no. 9, pp. 1712-1720, 2008.

[10] T. Nakayama, T. Kosugi, M. Gersch et al., "Dietary fructose causes tubulointerstitial injury in the normal rat kidney," American Journal of Physiology — Renal Physiology, vol. 298, no. 3, pp. F712-F720, 2010.

[11] Z. Ackerman, M. Oron-Herman, M. Grozovski et al., "Fructose-induced fatty liver disease: hepatic effects of blood pressure and plasma triglyceride reduction," Hypertension, vol. 45, no. 5, pp. 1012-1018, 2005.

[12] C. A. Roncal-Jimenez, M. Lanaspa, C. Rivard et al., "Sucrose induces fatty liver and type II diabetes in male Breeder rats independent of excess energy intake metabolism," Clinical and Experimental. In press.

[13] S. Reungjui, C. A. Roncal, W. Mu et al., "Thiazide diuretics exacerbate fructose-induced metabolic syndrome," Journal of the American Society of Nephrology, vol. 18, no. 10, pp. 27242731, 2007.

[14] T. Nakagawa, H. Hu, S. Zharikov et al., "A causal role for uric acid in fructose-induced metabolic syndrome," American Journal of Physiology - Renal Physiology, vol. 290, no. 3, pp. F625-F631, 2006.

[15] X. Ouyang, P. Cirillo, Y. Sautin et al., "Fructose consumption as a risk factor for non-alcoholic fatty liver disease," Journal of Hepatology, vol. 48, no. 6, pp. 993-999, 2008.

[16] M. F. Abdelmalek, A. Suzuki, C. Guy et al., "Increased fructose consumption is associated with fibrosis severity in patients with nonalcoholic fatty liver disease," Hepatology, vol. 51, no. 6, pp. 1961-1971, 2010.

[17] M. Dirlewanger, P. Schneiter, E. Jéquier, and L. Tappy, "Effects of fructose on hepatic glucose metabolism in humans," American Journal of Physiology - Endocrinology and Metabolism, vol. 279, no. 4, pp. E907-E911, 2000.

[18] C. B. Niewoehner and F. Q. Nuttall, "Mechanism of stimulation of liver glycogen synthesis by fructose in alloxan diabetic rats," Diabetes, vol. 35, no. 6, pp. 705-711, 1986.

[19] J. H. Youn, M. S. Youn, and R. N. Bergman, "Synergism of glucose and fructose in net glycogen synthesis in perfused rat livers," Journal of Biological Chemistry, vol. 261, no. 34, pp. 15960-15969, 1986.

[20] I. Hwang, H. Ho, B. B. Hoffman, and G. M. Reaven, "Fructoseinduced insulin resistance and hypertension in rats," Hypertension, vol. 10, no. 5, pp. 512-516, 1987.

[21] R. Hill, N. Baker, and I. L. Chaikoff, "Altered metabolic patterns induced in the normal rat by feeding an adequate diet containing fructose as sole carbohydrate," The Journal of Biological Chemistry, vol. 209, pp. 705-716, 1954.

[22] K. L. Stanhope, J. M. Schwarz, N. L. Keim et al., "Consuming fructose-sweetened, not glucose-sweetened, beverages increases visceral adiposity and lipids and decreases insulin sensitivity in overweight/obese humans," Journal of Clinical Investigation, vol. 119, no. 5, pp. 1322-1334, 2009.
[23] K. Morino, K. F. Petersen, and G. I. Shulman, "Molecular mechanisms of insulin resistance in humans and their potential links with mitochondrial dysfunction," Diabetes, vol. 55, supplement 2, pp. S9-S15, 2006.

[24] Y. Nagai, S. Yonemitsu, D. M. Erion et al., "The role of peroxisome proliferator-activated receptor $\gamma$ coactivator- $1 \beta$ in the pathogenesis of fructose-induced insulin resistance," Cell Metabolism, vol. 9, no. 3, pp. 252-264, 2009.

[25] Y. Y. Sautin, T. Nakagawa, S. Zharikov, and R. J. Johnson, "Adverse effects of the classic antioxidant uric acid in adipocytes: NADPH oxidase-mediated oxidative/nitrosative stress," American Journal of Physiology-Cell Physiology, vol. 293, no. 2, pp. C584-C596, 2007.

[26] S. E. Perez-Pozo, J. Schold, T. Nakagawa, L. G. SánchezLozada, R. J. Johnson, and J. L. Lillo, "Excessive fructose intake induces the features of metabolic syndrome in healthy adult men: role of uric acid in the hypertensive response," International Journal of Obesity, vol. 34, no. 3, pp. 454-461, 2010.

[27] B. P. Cummings, K. L. Stanhope, J. L. Graham et al., "Dietary fructose accelerates the development of diabetes in UCDT2DM rats: amelioration by the antioxidant, $\alpha$-lipoic acid," American Journal of Physiology-Regulatory Integrative and Comparative Physiology, vol. 298, no. 5, pp. R1343-R1350, 2010.

[28] Y. Takagi, A. Kashiwagi, Y. Tanaka, T. Asahina, R. Kikkawa, and Y. Shigeta, "Significance of fructose-induced protein oxidation and formation of advanced glycation end product," Journal of Diabetes and Its Complications, vol. 9, no. 2, pp. 87-91, 1995.

[29] R. C. Bell, J. C. Carlson, K. C. Storr, K. Herbert, and J. Sivak, "High-fructose feeding of streptozotocin-diabetic rats is associated with increased cataract formation and increased oxidative stress in the kidney," British Journal of Nutrition, vol. 84, no. 4, pp. 575-582, 2000.

[30] V. S. Malik, B. M. Popkin, G. A. Bray, J. P. Després, and F. B. $\mathrm{Hu}$, "Sugar-sweetened beverages, obesity, type 2 diabetes mellitus, and cardiovascular disease risk," Circulation, vol. 121, no. 11, pp. 1356-1364, 2010.

[31] M. B. Schulze, J. E. Manson, D. S. Ludwig et al., "Sugarsweetened beverages, weight gain, and incidence of type 2 diabetes in young and middle-aged women," Journal of the American Medical Association, vol. 292, no. 8, pp. 927-934, 2004.

[32] V. S. Malik, B. M. Popkin, G. A. Bray, J.-P. Després, W. C. Willett, and F. B. Hu, "Sugar-sweetened beverages and risk of metabolic syndrome and type 2 diabetes: a meta-analysis," Diabetes Care, vol. 33, no. 11, pp. 2477-2483, 2010.

[33] K. L. Teff, S. S. Elliott, M. Tschöp et al., "Dietary fructose reduces circulating insulin and leptin, attenuates postprandial suppression of ghrelin, and increases triglycerides in women," Journal of Clinical Endocrinology and Metabolism, vol. 89, no. 6, pp. 2963-2972, 2004.

[34] N. M. Avena, P. Rada, and B. G. Hoebel, "Sugar bingeing in rats," Current Protocols in Neuroscience/Editorial board, Jacqueline N. Crawley ... [et al.], chapter 9, Article ID Unit9.23, 2006.

[35] A. Shapiro, W. Mu, C. Roncal, K. Y. Cheng, R. J. Johnson, and P. J. Scarpace, "Fructose-induced leptin resistance exacerbates weight gain in response to subsequent high-fat feeding," American Journal of Physiology-Regulatory Integrative and Comparative Physiology, vol. 295, no. 5, pp. R1370-R1375, 2008.

[36] A. Shapiro, N. Tümer, Y. Gao, K.-Y. Cheng, and P. J. Scarpace, "Prevention and reversal of diet-induced leptin resistance with 
a sugar-free diet despite high fat content," British Journal of Nutrition, vol. 22, pp. 1-8, 2011.

[37] D. I. Jalal, G. Smits, R. J. Johnson, and M. Chonchol, "Increased fructose associates with elevated blood pressure," Journal of the American Society of Nephrology, vol. 21, no. 9, pp. 1543-1549, 2010.

[38] L. Chen, B. Caballero, D. C. Mitchell et al., "Reducing consumption of sugar-sweetened beverages is associated with reduced blood pressure: a prospective study among United States Adults," Circulation, vol. 121, no. 22, pp. 2398-2406, 2010.

[39] C. M. Brown, A. G. Dulloo, G. Yepuri, and J. P. Montani, "Fructose ingestion acutely elevates blood pressure in healthy young humans," American Journal of Physiology-Regulatory Integrative and Comparative Physiology, vol. 294, no. 3, pp. R730-R737, 2008.

[40] L. G. Sánchez-Lozada, E. Tapia, A. Jiménez et al., "Fructoseinduced metabolic syndrome is associated with glomerular hypertension and renal microvascular damage in rats," American Journal of Physiology-Renal Physiology, vol. 292, no. 1, pp. F423-F429, 2007.

[41] G. D’Angelo, A. A. Elmarakby, D. M. Pollock, and D. W. Stepp, "Fructose feeding increases insulin resistance but not blood pressure in Sprague-Dawley rats," Hypertension, vol. 46, no. 4, pp. 806-811, 2005.

[42] V. Farah, K. M. Elased, Y. Chen et al., "Nocturnal hypertension in mice consuming a high fructose diet," Autonomic Neuroscience, vol. 130, no. 1-2, pp. 41-50, 2006.

[43] A. K. Singh, H. Amlal, P. J. Haas et al., "Fructose-induced hypertension: essential role of chloride and fructose absorbing transporters PAT1 and Glut5," Kidney International, vol. 74, no. 4, pp. 438-447, 2008.

[44] M. Madero, S. E. Perez-Pozo, D. Jalal, R. J. Johnson, and L. G. Sanchez-Lozada, "Dietary fructose and hypertension," Current Hypertension Reports, vol. 13, no. 1, pp. 29-35, 2011.

[45] K. R. Bruckdorfer, I. H. Khan, and J. Yudkin, "Dietary carbohydrate and fatty acid synthetase activity in rat liver and adipose tissue," Biochemical Journal, vol. 123, no. 1, p. 7, 1971.

[46] S. S. Kang, R. G. Price, K. R. Bruckdorfer, N. A. Worcester, and J. Yudkin, "Dietary induced renal damage in the rat," Proceedings of the Nutrition Society, vol. 36, no. 1, p. 27, 1977.

[47] M. S. Gersch, W. Mu, P. Cirillo et al., "Fructose, but not dextrose, accelerates the progression of chronic kidney disease," American Journal of Physiology-Renal Physiology, vol. 293, no. 4, pp. F1256-F1261, 2007.

[48] V. Douard, A. Asgerally, Y. Sabbagh et al., "Dietary fructose inhibits intestinal calcium absorption and induces vitamin D insufficiency in CKD," Journal of the American Society of Nephrology, vol. 21, no. 2, pp. 261-271, 2010.

[49] D. A. Shoham, R. Durazo-Arvizu, H. Kramer et al., "Sugary soda consumption and albuminuria: results from the national health and nutrition examination survey, 1999-2004," PLoS ONE, vol. 3, no. 10, Article ID e3431, 2008.

[50] S. Vasdev, V. Gill, S. Parai, L. Longerich, and V. Gadag, "Dietary vitamin E and C supplementation prevents fructose induced hypertension in rats," Molecular and Cellular Biochemistry, vol. 241, no. 1-2, pp. 107-114, 2002.

[51] J. P. Forman, H. Choi, and G. C. Curhan, "Fructose and vitamin $\mathrm{C}$ intake do not influence risk for developing hypertension," Journal of the American Society of Nephrology, vol. 20, no. 4, pp. 863-871, 2009.

[52] K. A. Lê, D. Faeh, R. Stettler et al., "A 4-wk high-fructose diet alters lipid metabolism without affecting insulin sensitivity or ectopic lipids in healthy humans," American Journal of Clinical Nutrition, vol. 84, no. 6, pp. 1374-1379, 2006.
[53] E. T. Ngo Sock, K. A. Lê, M. Ith, R. Kreis, C. Boesch, and L. Tappy, "Effects of a short-term overfeeding with fructose or glucose in healthy young males," British Journal of Nutrition, vol. 103, no. 7, pp. 939-943, 2010.

[54] G. Silbernagel, J. Machann, S. Unmuth et al., "Effects of 4week very-high-fructose/glucose diets on insulin sensitivity, visceral fat and intrahepatic lipids: an exploratory trial," British Journal of Nutrition, pp. 1-8, 2011.

[55] J. Hallfrisch, K. Ellwood, and O. E. Michaelis, "Plasma fructose, uric acid, and inorganic phosphorus responses of hyperinsulinemic men fed fructose," Journal of the American College of Nutrition, vol. 5, no. 1, pp. 61-68, 1986.

[56] J. Hallfrisch, K. C. Ellwood, O. E. Michaelis et al., "Effects of dietary fructose on plasma glucose and hormone responses in normal and hyperinsulinemic men," Journal of Nutrition, vol. 113, no. 9, pp. 1819-1826, 1983.

[57] J. Hallfrisch, S. Reiser, and E. S. Prather, "Blood lipid distribution of hyperinsulinemic men consuming three levels of fructose," American Journal of Clinical Nutrition, vol. 37, no. 5, pp. 740-748, 1983.

[58] K. A. Lê, M. Ith, R. Kreis et al., "Fructose overconsumption causes dyslipidemia and ectopic lipid deposition in healthy subjects with and without a family history of type 2 diabetes," American Journal of Clinical Nutrition, vol. 89, no. 6, pp. 17601765, 2009.

[59] A. Korieh and G. Crouzoulon, "Dietary regulation of fructose metabolism in the intestine and in the liver of the rat. Duration of the effects of a high fructose diet after the return to the standard diet," Archives Internationales de Physiologie, de Biochimie et de Biophysique, vol. 99, no. 6, pp. 455-460, 1991.

[60] F. Stirpe, E. Della Corte, E. Bonetti, A. Abbondanza, A. Abbati, and F. De Stefano, "Fructose-induced hyperuricaemia," Lancet, vol. 2, no. 7686, pp. 1310-1311, 1970.

[61] K. Ushijima, J. E. Riby, T. Fujisawa, and N. Kretchmer, "Absorption of fructose by isolated small intestine of rats is via a specific saturable carrier in the absence of glucose and by the disaccharidase-related transport system in the presence of glucose," Journal of Nutrition, vol. 125, no. 8, pp. 2156-2164, 1995.

[62] J. J. Rumessen and E. Gudmand-Hoyer, "Absorption capacity of fructose in healthy adults. Comparison with sucrose and its constituent monosaccharides," Gut, vol. 27, no. 10, pp. 11611168, 1986. 


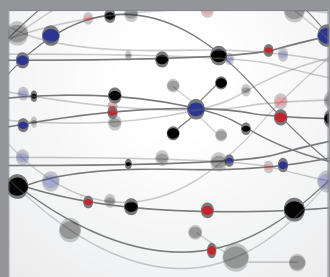

The Scientific World Journal
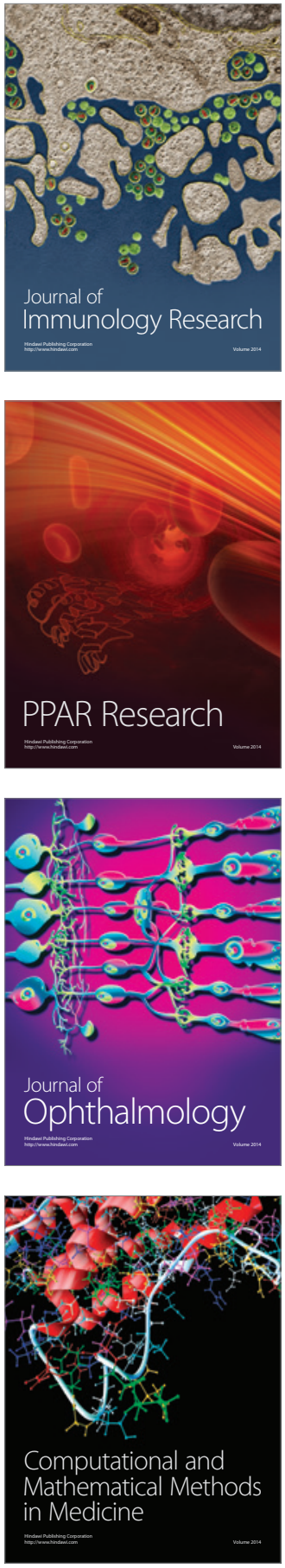

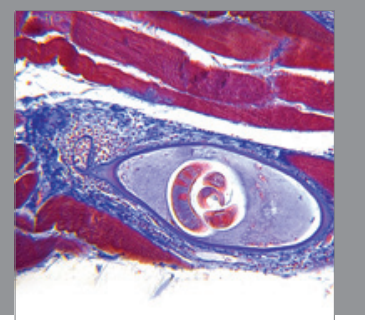

Gastroenterology

Research and Practice
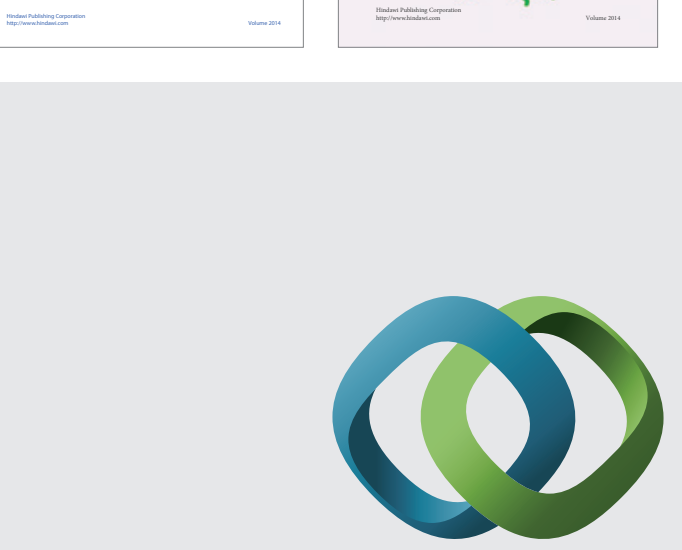

\section{Hindawi}

Submit your manuscripts at

http://www.hindawi.com
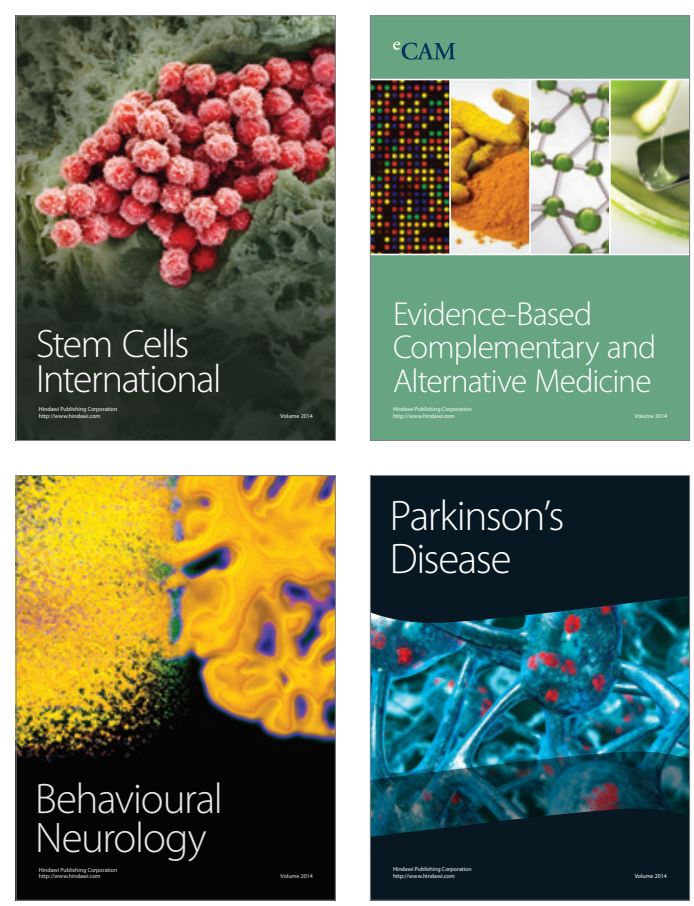

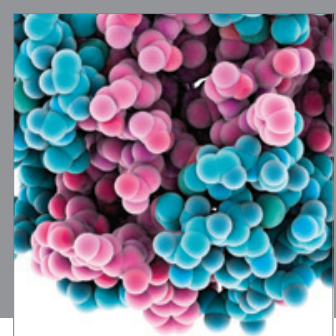

Journal of
Diabetes Research

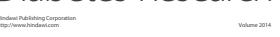

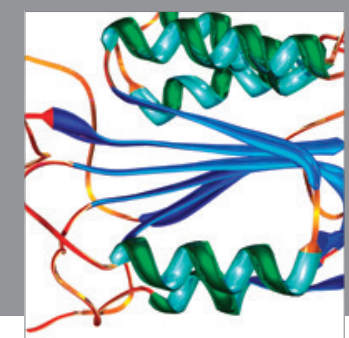

Disease Markers
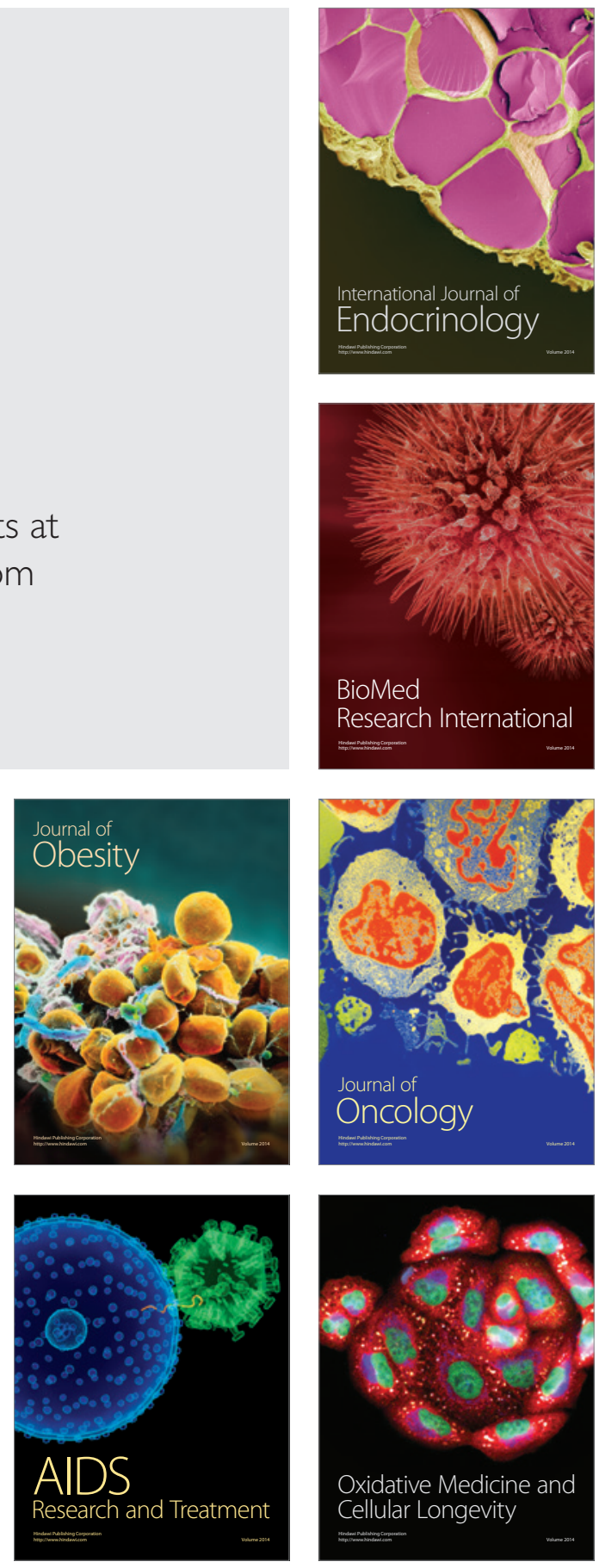